\title{
Emmetropisation, axial length, and corneal topography in teenagers with Down's syndrome
}

\author{
Stephen J Doyle, John Bullock, Cath Gray, Alison Spencer, Cliff Cunningham
}

\begin{abstract}
Aim-To study the refractive status and corneal topography in Down's syndrome. Method-A matched cohort subgroup of 50 individuals with Down's syndrome in the Manchester area aged 15-22 years was studied by refraction, corneal topography, A-scan biometry, slit lamp examination, and orthoptic examination.

Results-(1) A linear relation was found between axial length and spherical equivalent refraction. There was no statistical relation between keratometry and the axial length. (2) $80 \%$ of the group had a hyperopic refraction (mean $+2.46 \mathrm{D}$, range +0.5 to $+7.5 \mathrm{D}) ; 18 \%$ were myopic (mean $-2.75 \mathrm{D}$, range -0.5 to $-8.0 \mathrm{D}$ ); and $2 \%$ were emmetropic (within plus or minus $0.5 \mathrm{D}$ of zero). The overall mean spherical equivalent refraction was +1.43 (SD 2.86) D. 63\% of eyes could see $6 / 12$ or better and $66 \%$ of the individuals had a binocular vision of $6 / 12$ or better. (3) Corneal topography was generally of a regular "bow tie" pattern, but there was a high incidence of oblique cylinders. Mean cylinder strength was 1.14 (1.15) D. (4) The prevalence of overt keratoconus was $2 \%$. $6 \%$ had corneal topography with inferior steepening which may be a preclinical keratoconic process.

Conclusions-In this cohort of late teenagers with Down's syndrome, emmetropisation has failed to occur in most individuals. In a similar aged group of non-disabled individuals one would expect about $83 \%$ emmetropic (plus or minus $0.25 \mathrm{D}), 13 \%$ myopic, and $4 \%$ hyperopic. The wide spread of oblique cylinders and the small proportion of with the rule
\end{abstract}

Accepted for publication 19 November 1997

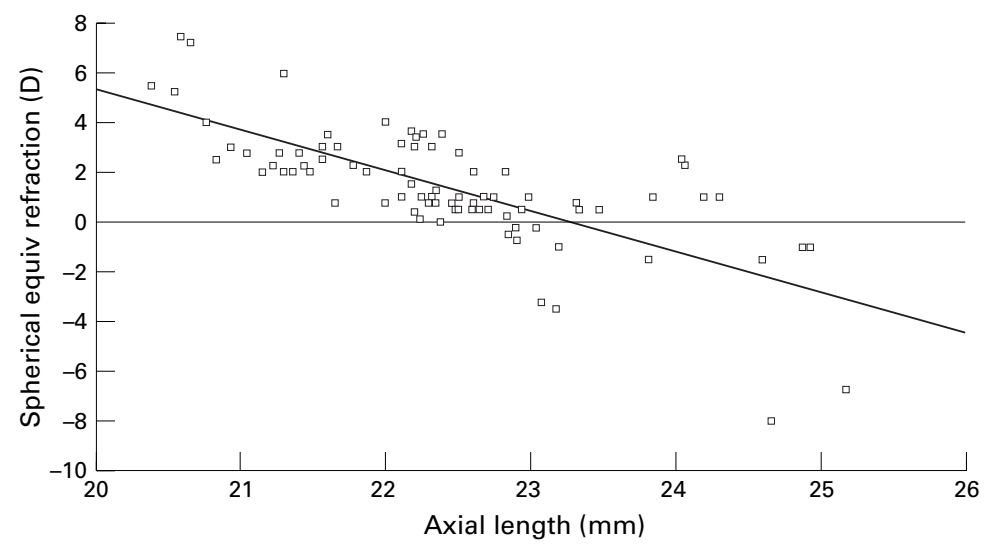

Figure 1 Plot of spherical equivalent refraction $v$ axial length as measured by $A$-scan biometry. astigmatism is probably related to this failure of emmetropisation. The prevalence of $2 \%$ keratoconus in Down's syndrome compares with that found by other authors of between 5.5 and $15 \%$. The $6 \%$ with inferior steepening on topography will be followed up over the next few years to see if there is any development of clinical keratoconus. Hence we will see if corneal topography is useful as a screening tool for preclinical keratoconus in this high risk group.

(Br f Ophthalmol 1998;82:793-796)

Individuals with Down's syndrome have been reported to have a higher incidence of refractive errors ${ }^{1-3}$ and keratoconus. ${ }^{4-6}$ All these studies have been on random groups, presenting to normal clinical practice or found in various institutions. We present some findings from a study on a representative sample of the Greater Manchester Down's Syndrome Cohort, all of whom resided in the family home.

\section{Method}

A cohort consisting of $90 \%$ of the total known Down's syndrome births in Greater Manchester over the 7 year period between August 1973 and August 1980 had been studied since birth by the Hester Adrian Research Centre of the University of Manchester and comprised 181 individuals. Their medical, social, and psychological histories were well known because of this study. ${ }^{7}$ By September 1995, 118 of these were still living locally, the rest having been lost to the study because of movement out of the area or death. All 118 were contacted by post and in the period allocated for the study, 57 had been studied, of which 50 were selected and agreed by the original researchers of the cohort to be representative of the total cohort for age, mental ability, general health, and social class. This subgroup (29 male, 21 female) of ages 15-22 years (mean 17.4 years) was studied by refraction, orthoptic examination, corneal topography, A-scan biometry, and slit lamp examination. Refraction was done in the normal way, without cycloplegia. Corneal topography was done using a TMS-1 machine. Biometry was done using a Storz A-scan ultrasound machine. Slit lamp examination and fundal examination through the undilated pupil using an indirect $78 \mathrm{D}$ lens was also done.

Results

A linear relation was found between axial length and spherical equivalent refraction (Fig 1). 


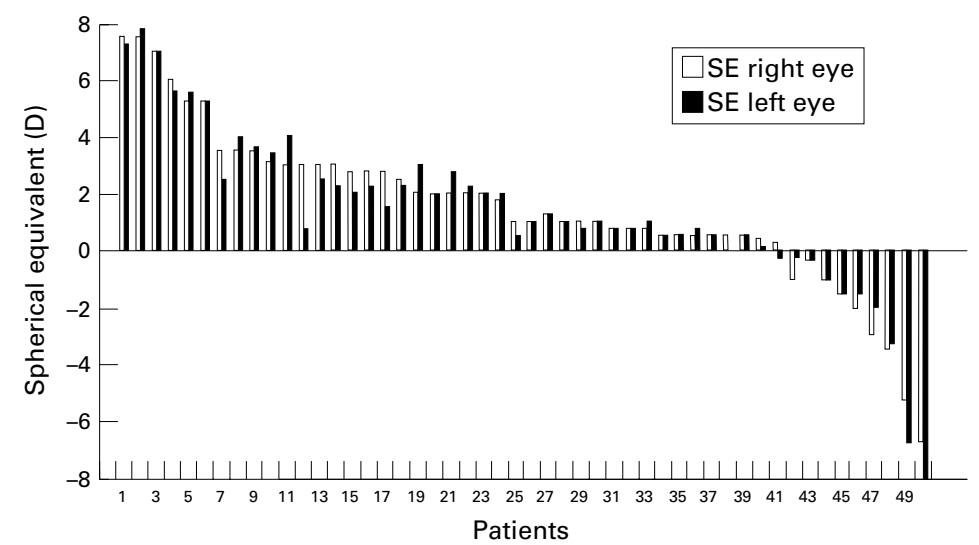

Figure 2 Bar chart of spherical equivalent refraction for each eye.

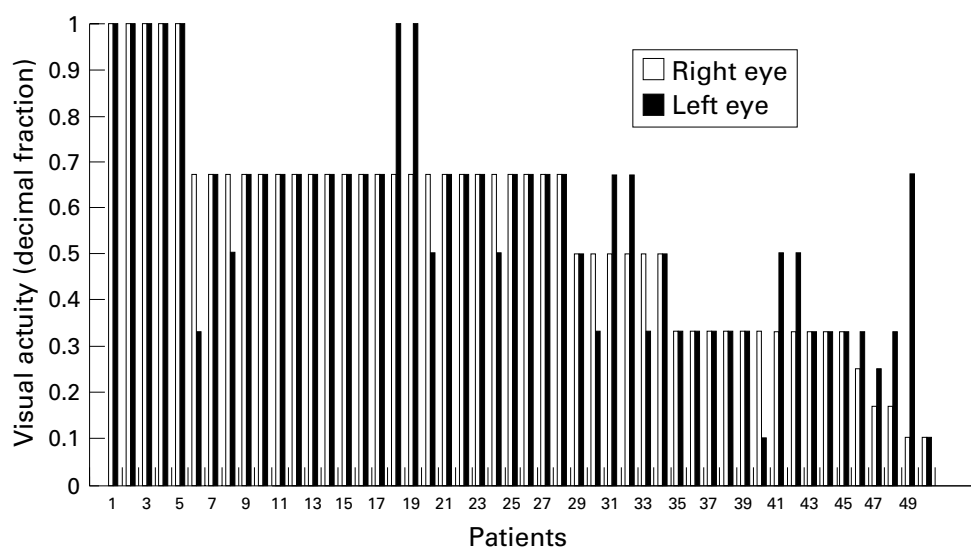

Figure 3 Bar chart of visual acuity for each eye.

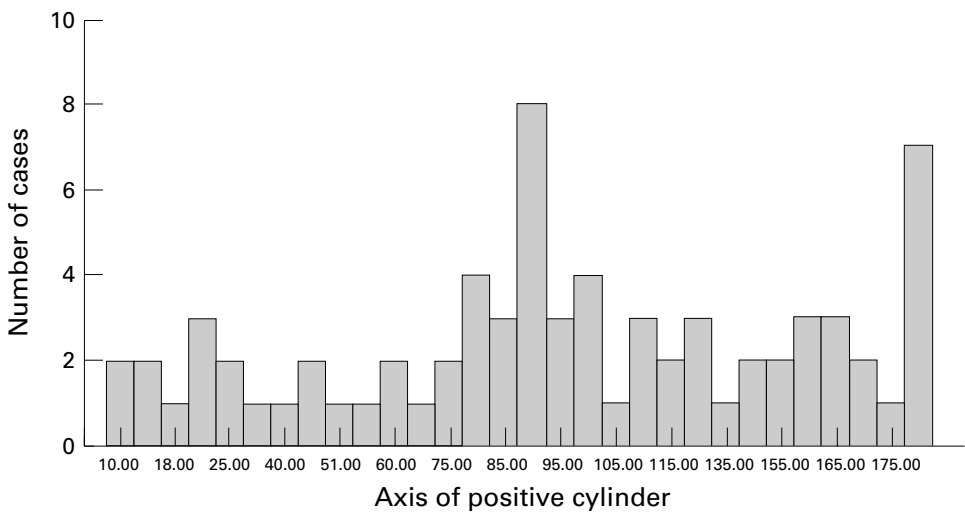

Figure 4 Bar chart of axes of the refractive cylinders.

Forty $(80 \%)$ of the group had a hypermetropic refraction ( mean $+2.46 \mathrm{D}$, range +0.5 to $+7.5 \mathrm{D})$; nine $(18 \%)$ were myopic (mean $-2.75 \mathrm{D}$, range -0.5 to $-8.0 \mathrm{D})$; one $(2 \%)$ was emmetropic (within plus or minus $0.5 \mathrm{D}$ of zero). The overall mean spherical equivalent refraction was +1.43 (SD 2.86) D (Fig 2). In terms of visual acuity, $63 \%$ of eyes could see $0.5(6 / 12)$ or better and $66 \%$ of the individuals had a binocular vision of $6 / 12$ or better (Fig 3). Visual acuity was measured with a Snellen chart at 6 metres in 40 cases, SheridanGardiner cards in six cases, two used reduced Snellen, and two used Cardiff charts.

Anisometropia had a mean of $0.4 \mathrm{D}$ (SD $0.47 \mathrm{D}, \max 1.5 \mathrm{D}) ; 58 \%$ wore glasses at least some of the time.
Corneal topography was generally of a regular "bow tie" pattern that fitted the optical refraction, but there was a high incidence of oblique cylinders with $38 \%$ of eyes having their axis outside $10^{\circ}$ from the orthogonal axes; $22 \%$ had cylinders "with the rule" (plus or minus $10^{\circ}$ of $90^{\circ}$ ) and $39 \%$ had cylinders "against the rule" (plus or minus $10^{\circ}$ of $180^{\circ}$ ) (Fig 4 ).

Mean cylinder strength was 1.14 (SD 1.15) D (Fig 5). Topography was successful in all but one subject and he had minimal astigmatism. Hence, it was felt unlikely that he would have any irregular topography. Average keratometry for the group was 43.97 (2.17) D. There was no statistical relation between keratometry and the axial length.

There was one $(2 \%)$ overt keratoconus (Fig $6)$. Three $(6 \%)$ had corneal topography with inferior steepening which may be a preclinical keratoconic process (Fig 7).

Two $(4 \%)$ had childhood squint operations, although neither of these had any amblyopia. There were three amblyopic eyes in three patients, two associated with large cylinders and small A esotropia patterns. The other amblyope was in a V esotrope. There were four other A esophorias, giving a total of six $(12 \%)$ with an A esotropic pattern. There were no exophorias or exotropias. Five $(10 \%)$ had latent nystagmus.

Fourteen $(28 \%)$ had minor bilateral lens opacities of no visual significance in any case. Five $(10 \%)$ had "flake" lens opacities, two (4\%) had sutural changes, and seven (14\%) had "blue dot" opacities. The posterior poles were normal in all cases. No optic disc had a cup/disc ratio of greater than 0.3 .

In terms of general health, $36 \%$ (18) had conductive hearing loss; this was mostly due to repeated middle ear infections, and nine (18\%) had had grommets, tonsillectomy, and/or adenoidectomy.

\section{Discussion}

The linear relation between refraction and axial length (and also vitreous cavity length) in Down's syndrome is also found in the normal population. ${ }^{8}$ The process of emmetropisation in Down's syndrome in the first 2 years of life has been studied by Woodhouse's group at the University of Wales, Cardiff School of Optometry. ${ }^{9}$ They have shown that the distribution of refractive errors among infants with Down's syndrome is similar to the norm; but, rather than narrowing with age as in the normal population, the distribution widens, and the prevalence of refractive errors increases in children with Down's syndrome. In our cohort of teenagers with Down's syndrome, it is clear that emmetropisation has failed to occur in most individuals. In a similar aged group of non-disabled children one would expect about $83 \%$ emmetropic (plus or minus 0.25 D), $13 \%$ myopic, and $4 \%$ hyperopic. ${ }^{10}$ Cylinders also tend to decrease with emmetropisation, but this also appears not to have occurred with this group with a mean cylinder of 1.14 (1.15) D. The wide spread of oblique cylinders and the small proportion of with the rule astigmatism is again 


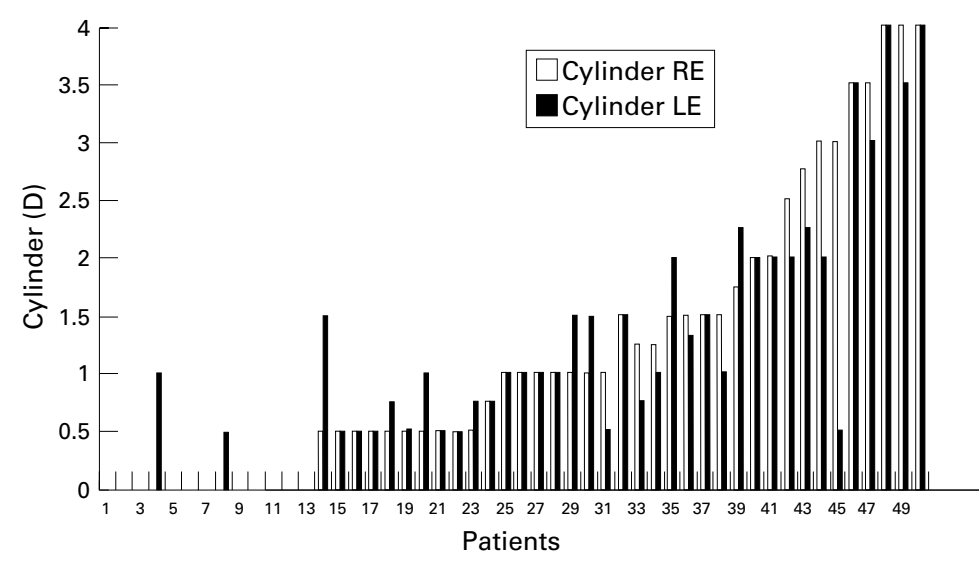

Figure 5 Bar chart of magnitude of the refractive cylinders.

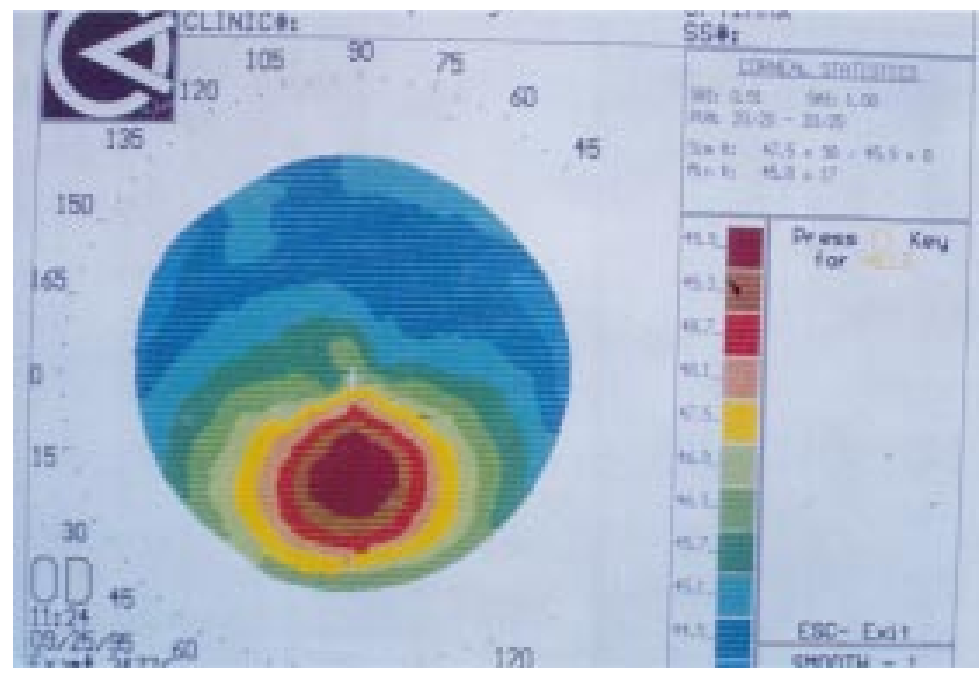

Figure 6 Corneal topography of subject with clinical keratoconus.

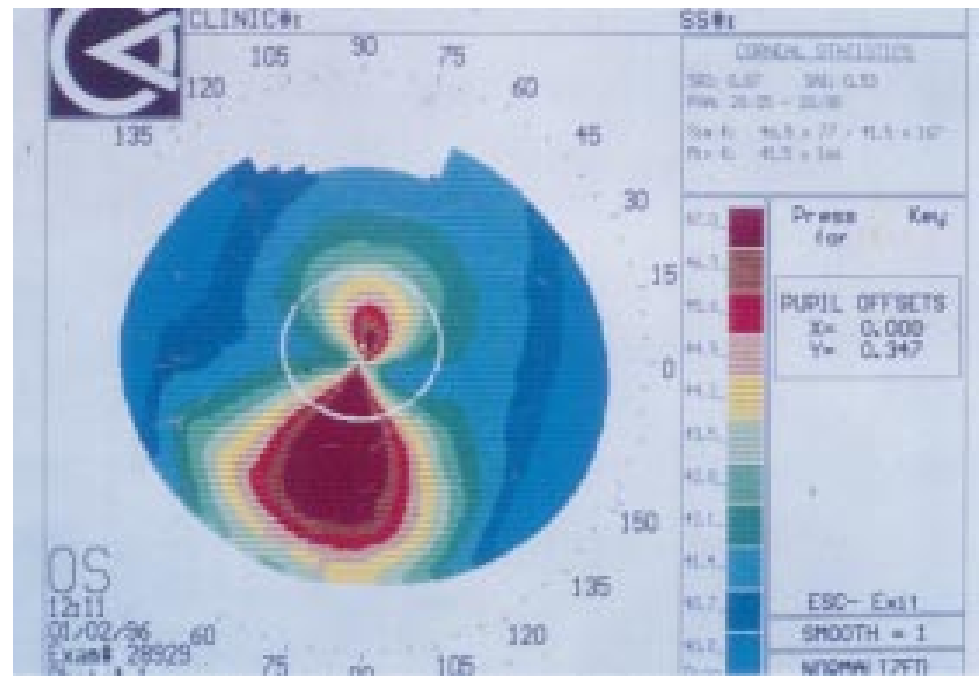

Figure 7 Corneal topography of subject with inferior steepening

probably related to this failure of emmetropisation. It is known that corneal topography changes from with the rule to against the rule with aging in the normal population ${ }^{11}$ and individuals with Down's syndrome age more rapidly than normal. However, it is unlikely that this is the cause among these teenagers as the onset of more rapid aging does not occur until much later.
This group was part of a cohort that had been closely followed since birth by the Hester Adrian Research Centre and had appropriate intervention at an early stage. Often, Down's individuals do not develop as they should because of poor hearing and/or vision. Screening in childhood should hence be especially thorough as they are prone to middle ear problems and refractive errors, either of which can stunt intellectual and social development. This group performed visually surprisingly well, with two thirds seeing $6 / 12$ or better. We think that visual performance has been maximised by early refraction and appropriate glasses in almost all cases, with good follow up, and it emphasises the importance of good early ophthalmic care for those with Down's syndrome.

It is interesting that the posterior segments were normal in all cases. All the ocular pathologies seem to be confined to the anterior segment. We do not know if there is a reason for this or whether it is a chance finding.

The prevalence of keratoconus in Down's syndrome has been reported as being between 5.5 and $15 \%$ by various authors ${ }^{4-6}$ compared with the general population of about 50 per $100000(0.05 \%) .{ }^{12}$ Many reports in the literature suggest an abnormality in collagen metabolism in patients with keratoconus. The gene encoding the $\alpha-1$ chain of type VI collagen, a major constituent of the corneal stroma, is on chromosome 21 at locus 21q22.3. As Down's has a trisomy 21, it has been speculated there might be a connection between this gene and the higher incidence of keratoconus in Down's syndrome. Indeed, one team has done linkage analysis to see if a mutation of this collagen VI gene contributed to a keratoconus occurring in three generations of one family. ${ }^{13}$ The study excluded a gene locus for keratoconus on the most telomeric region of chromosome 21 in this family group, but the interesting speculation remains. Keratoconus is essentially a post-pubertal disease and mostly presents between the ages of 15 and 25 years (Manchester Royal Eye Hospital Keratoconus Survey, 1995, unpublished) The fact that we found one $(2 \%)$ overt keratoconic is not surprising. What is more interesting is to see whether the three with inferior steepening on topography become truly keratoconic over the next few years. With corneal topography becoming more widely available, the possibility of screening a higher risk group for keratoconus such as individuals with Down's syndrome becomes more feasible. Added risk factors for keratoconus development, as in the non-Down's population, are atopy, an eye rubbing habit, and myopic shift in refraction.

Individuals with Down's syndrome showing any of these characteristics should probably have corneal topography in their mid to late teens as a screen for possible early keratoconus.

Our understanding of emmetropisation and the pathogenesis of keratoconus is at best sketchy and much work remains to be done. 
Catalano RA. Down syndrome. Surv Ophthalmol 1990;34:385-98.

Shapiro $\mathrm{MB}$ France TD. The ocular features of Down's syndrome. Am f Ophthalmol 1985;99:659-63.

3 Eissler R, Longnecker JP. The common eye findings in mongolism. Am f Ophthalmol 1962;54:398-406.

4 Cullen JF, Butler HG. Mongolism (Down's syndrome) and keratoconus. Br f Ophthalmol 1963;47:321-30.

5 Pierse D, Eustace P. Acute keratoconus in mongols. $\mathrm{Br} \mathcal{F}$ Ophthalmol 1971;55:50-4.

6 Walsh SZ. Keratoconus and blindness in 469 institutionalised subjects with Down's syndrome and other causes of mental retardation. f Ment Defic Res 1981;25:243-51.

7 Turner S, Sloper P, Knussen C, et al. Health problems in children with Down's syndrome. Child, Care, Health and Development 1990;16:83-97.

8 Hosaka A. The growth of the eye and its components. Acto Ophthalmol Suppl 1988;185:65-8.
9 Woodhouse JM, Pakeman VH, Parker M, et al. Refractive errors in infants and young children with Down's syndrome. MAMH Congress "The mentally retarded in 2000's Society", Rome 1994 and personal communication.

10 Teasdale TW, Goldschmidt E. Myopia and its relationship to education, intelligence and height. Acta Ophthalmol Suppl 1988;185:41-3.

11 Hayashi K, Hayashi H, Hayashi F. Topographic analysis of the changes in corneal shape due to ageing. Cornea the changes in

12 Kennedy RH, Bourne WM, Dyer JA. A 48 year clinical and epidemiological study of keratoconus. Am $\mathcal{f}$ Ophthalmol 1986;101:267-73.

13 Rabinowitz YS, Maumenee IH, Lundergan MK, et al. Molecular genetic analysis in autosomal dominant keratoconus. Cornea 1992;11:302-8. 